\title{
THE CONSOLIDATING POWER OF VALUES AMONG MUSLIMS IN BULGARIA
}

\author{
Assoc. Prof. Veselin Bosakov PhD \\ Institute for the Study of Societies and Knowledge, \\ Sofia 1000, Bulgaria \\ +359898944 337; vesobos@abv.bg
}

\begin{abstract}
The results of the analyses of European Values Study data indicate significant differences between the social and value profile of Eastern Orthodox Christians and the Muslim community in Bulgaria. For Muslims, religion is no longer a value in itself but a complete environment, which determines the attitude towards other values and relations.
\end{abstract}

Keywords: values, Islam, religion, tolerance, faith

\section{The Social Profile of Religiousness}

The fourth wave of the European Values Study (Fotev 2009) can serve to orient us to a deeper and more subtle understanding of the importance of religious morality and of the answers it provides in the face of the daily challenges of secular life. Declared personal affiliation to a religion does not in itself imply active religious practice or, even less, a religious identity covering all elements of social conduct of the faithful (Bosakov 2015). The social profile of the respondents who have indicated affiliation to Islam can be defined distinctly enough. According to the survey findings, 73,3\% of all respondents who answered this question defined themselves as religious. More often religious are women $(78,0 \%$ of women have indicted they are religious, and $68,1 \%$ of men) and people living in villages $(78,3 \%$ compared with $71,9 \%$, living in 'other cities' and 68,0\% living in Sofia). At the same time, with respect to age the figures are notably dynamic. The smallest share of those who indicated they were religious was in the age group between 25 and $39(69,7 \%)$. In terms of their biographies, this is the age group of the people whose value attitudes and religious convictions were shaped shortly before and at the very start of the posttotalitarian transformations in Bulgarian society. In all other age groups the registered degree of religiousness is higher than the average result for all surveyed persons. Closest to the average is the group of people age 40 to 54 at the time of fieldwork, in the spring of 2008, when the survey was conducted: $73,5 \%$ of them indicated they were religious.

The highest percentages for religiousness were registered among the two age groups with very differing life experiences: the respondents above the age of 55 and the youngest, between 18 and 24 years of age.

In the oldest age groups, the registered values are, respectively, 75,6\% among those aged 55 to 69 , and $74,8 \%$ among those above 70 . In the youngest group of respondents, 74,4 \% defined themselves as religious. This is also the group with the lowest registered nonreligiousness: only $22,6 \%$ of them indicated they did not belong to any religious confession. ${ }^{1}$

According to the survey results, the social profile of Muslims repeats the general characteristics of religiousness, but with some important overtones. The biggest proportion of Muslims is that in

\footnotetext{
${ }^{1}$ This figure is lower than the average for the whole population $-26,0 \%$, and than the average of each of the other age groups.
} 
the lowest age group, 18 to $24(18,6 \%$ of all surveyed persons in this age group indicated they were Muslims). Smaller shares, yet higher than the average for all other surveyed persons, are those of Muslims aged 25 to $39(13,8 \%)$ and aged 40 to $54(14,9 \%)$. In contrast with the traditional notions of non-Muslims regarding the religiousness of Muslims in Bulgaria by age, this study has shown relatively lower figures in the older age groups. Among the respondents aged over 70 , the share of Muslims was only 7,3\%, while in the next age group (people between 55 and 69) it was 9,9\%.

The distribution of Muslims by type of settlement is not significantly different from the general profile of respondents who indicated themselves as religious. Considerably lower than the normal distribution is the percentage of Muslims in Sofia and the other cities: respectively $1,4 \%$ and $5,8 \%$. But in villages, $31,4 \%$ of those who indicated their religious affiliation were Muslims.

In generalizing the information of the study regarding the social profile of the religious, we may say that Muslims in Bulgaria today are more often young people (aged between 18 and 24) or middle-aged people (between 40 and 54), and people living mostly in rural regions of the country. The profile of Eastern Orthodox Christians shows important differences: they are more often elderly people (aged 55 or more), living mostly in Sofia and other cities. Whereas among Muslims the percentage of men is slightly higher than of women, among the Christians religiousness is considerably more often a characteristic of women.

The two social profiles, those of people indicating they are Christians and those indicating Islamic affiliation, reveal significant differences. In the course of post-totalitarian transformation, the social distances between the various religious communities have changed. Hence it is possible to formulate a research hypothesis that the growing social disproportions such as those along the line centre-periphery are becoming more important factors for the value differences between the two religious groups. It is also possible to assume that the age distances will continue to have an impact in the same direction (Galabov 2007a). The aims of this analysis do not include the strict identification of these trends in the Muslim group, but the findings do give us reason to set this research question as a topic for future studies. Their partial social isolation, in which Muslims consolidate their value orientations with respect to Islam, has a different influence on their willingness for strict observance of religious rules. In this sense, regardless of the declared religious affiliation, in the Muslim communities there are on-going processes of differentiation, which are of considerable research interest.

\section{Religious tolerance}

Of determining importance for the problems we are concerned with here is the general correspondence between shared moral principles and the degree to which religiousness and religious morality serve in structuring certain value attitudes among Muslims.

The comparison between the results obtained for Eastern Orthodox Christians and for Muslims show different profiles for the two groups as regards the strict obedience to moral principles. The greatest share of Christians is that of respondents who indicated they have a relativistic perspective on morals, so that the qualification of good and evil entirely depends on the circumstances. This view is least supported by Muslim respondents. Among them, the largest percentage indicated they judged good and evil categorically, but with the reservation that deviating from the guidelines is justified by special circumstances. This view is also shared by a considerable portion of the 
Christian respondents. But Christians are also the ones who least often express support for categorical moral judgments. It is in the context of this general moral perspective that the respondents' attitude to the other religion and the correctness of their own religion can be inscribed.

The general level of declared religious tolerance in Bulgarian society, judging by the findings of this study, seem relatively high. The results for the question regarding whether there is only one true religion and the truth that one or all religions have to offer, show that, compared with respondents of other religions, Muslims are more willing to accept the idea that 'there is only one true religion but other religions may hold some truth'. Among Eastern Orthodox Christians, this view and the view that 'there is only one true religion' are supported equally. Coming second in the support of Muslim respondents is the option that 'there is not one true religion but all religions contain some basic truths'. As could be expected, there is almost negligible support among Muslims of the view that none of the world religions contain truths about the basic questions.

These results confirm the hypothesis that there are significant differences in the way in which those who have defined themselves as Christians perceive their own and other religions. There is a slight prevalence among Christians of the view that 'there is only one true religion, but other religions also contain some truths'. This is the view most often supported by Muslim respondents. The second most often supported view is that 'there is not only one true religion, but all great world religions contain some basic truths'. At least at a declarative level, the representatives of these two religions in Bulgaria are willing to acknowledge and value the importance of other faiths, but it seems that among Muslims, at least judging by their answers to this question, this attitude is more clearly expressed than among the respondents who have defined themselves as Eastern Orthodox Christians.

The relativistic attitude registered as widely present among Christian respondents does not correspond to a higher degree of religious tolerance. The comparison of these aspects, essential for our discussion, shows that what serves as a basis for religious tolerance here is, to a far greater degree, the view that there are clear criteria of good and evil, combined with an understanding that specific circumstances can lead to deviations from these moral norms.

The survey results delineate significant differences between the social and value profile of Eastern Orthodox Christians and the Muslim community in Bulgaria. In this survey, for an important share of the respondents who define themselves as Muslims, religion is no longer a value in itself but a complete environment, which determines the attitude towards other values and relations. Religious morality structures the new models of participation and forms of solidarity (Fotev 2003). While the Orthodox Christians mostly have a traditional respect for the norms of faith, among an important part of the Muslims religion is becoming a value scale and a core of social activity in general.

Analysis shows that the measure of declared tolerance is much higher than it appeared to be in past years - or at least in past surveys our desire to discern enduring processes of social integration amidst cultural difference blunted our critical perceptiveness about some of the findings. During a relatively long period of time, the importance of spatial closeness in the everyday reality of cultural variety has been preserved. In this sense, the attitude towards Islam in Bulgaria is confronted with the far more significant issue of the limits of a positive overcoming of the fear of the other. 
Do we have reasons to refer to a new Islamic culture in Bulgaria, or is it more a matter of a specific kind of religious modernization evolving, which preserves the basic postulates of faith, shifting them into a new social context and building a space of dialogue with the democratic values that are being established in contemporary Bulgarian society?

At the same time, the attachment to secular values remains relatively unstable. While we do have reason to consider that, overall, Bulgarian society is in a process of rethinking its attitude to religion, this applies to a much greater degree to Muslims. The mediating complex of factors that most probably accelerate certain processes of consolidation of the religious community is connected with its partial social isolation, its specific profile of professional, civic, and political activity. Though we have no reason to believe there is a direct causal link between these social phenomena, we may assume they unfold in parallel, and under certain conditions exert a mutual influence on their own course of development and form.

The relative social isolation of significant groups of Muslims is accelerating the agreement on certain reference values and is helping the process of transmitting those values from generation to generation, regardless of the different life experience and social experience of the separate communities. Along with this, at every level of achieved consensus on values in the Muslim community, there is a corresponding change in attitudes to the social environment. We may judge of the dynamics of these processes through secondary analysis of the results of previous surveys and also by differences registered by age groups.

Regardless of whether we opt for a diachronic or synchronic research perspective, we may envisage our further research efforts in the context of relations between social solidarity and religious identity, between effective interaction and the preservation of a religious community identity. Justifications for such a perspective are provided us by the results of this study, which show the prevalent value of 'work' and 'family' as the community's reference points for personal fulfillment.

The leading importance of religion among other values determines to various degrees the importance of topics such as leisure time, relations with friends, and the striving for personalized forms of social self-expression. Together with this, the Muslims' partial social isolation enhances mistrust of people and groups that are different from one's own and hence accelerates the processes of community consolidation. The risks involved in this specific situation could consist in the formation of negative attitudes towards religious and cultural difference, but also in the increase of the existing social distances (Pamporov 2009).

In the context of the growing importance of Islamic religious morality and the relatively low degree of Muslims' civic participation, it may be presumed Muslims would give greater attention to the religious education of their children. The findings show that among the younger generations of the Muslim communities in Bulgaria there is now a more active and meaningful relation to religious practice and a clearer willingness to follow its rules.

All this gives us reason to formulate new research questions connected with the interaction between the emerging value attitudes and the process of social realization of the youngest generations within the Muslim milieu. Foremost, the question is how the values of Islam and notions of personal success 
are combined and joined together in the life plans and strategies of young people?

In the context of growing social inequalities, to what degree would the existing experience and culture of dialogue between religions in Bulgarian society promote the process of social integration of Muslims? Do the registered value orientations of Muslims (Fotev 2009) correspond - and, if so, in what degree - to traditional notions about Islam in Bulgaria, or is there rather a mobilization of religious affiliation that is dominated by modernization processes in the Islamic community? Can we reasonably expect there will be a growing influence of the religious institutions on the conduct of members of the Muslim community? And, above all, to what degree might the dialogue and interaction between the traditional religions in Bulgaria provide the necessary resource for modernization?

But the general research framework and theoretical scope in which these investigations can be inscribed remains, as ever, connected with the global problem of Islamic modernity. The achievement of a dynamic equilibrium between religious morality and social changes will continue to be a fundamental issue, with reference to which all other research perspectives can find a place.

\section{Religious faith}

Significant changes are taking place in traditional Bulgarian Islam. One of the main agents of these changes today are the young Muslims who are still students in secondary schools and universities. Through this future spiritual elite of the Muslim community, new dimensions and new dynamics of this community's integration process will emerge and be asserted. The attitudes and positions of these young people, their values, will define to a considerable degree the directions of the process of integration of religious communities into the secular, democratic political model. That is why part of the efforts of researchers for interpreting the problem of the integration of the Muslim community in contemporary Bulgarian society will increasingly have to be focused on an analysis of the representations, justifications, and argumentations of the members of the spiritual and intellectual elite of the Muslim community in Bulgaria.

The initial assumptions that set the boundaries of this analysis are defined by the understanding that the so-called folk Islam in our country is being subjected to a fundamental rethinking in the context of modern democratic development and of the impact of contradictory phenomena which we have defined as a new Islamic culture and which mirror the effort to construct a specific Islamic modernity (Bosakov 2006; 2010; 2015 ). Together with this, we share the view that the Muslim community in our country is a unity only in the representations of nonMuslims. The internal differentiation and fragmentation of the contemporary Islamic lifeworld is a fact the fundamental importance of which is often underestimated. That is precisely why one object of the researcher's interest in this study is the internal heterogeneity of the representation of the unifying impact of religious education in the Muslim social environment.

The basic themes that shape the research efforts in this direction are formulated around the distances between meanings in the interpretation of democratic civic and secular values on one hand, and observance of the religious canon on the other. The social realities of the attitude towards Islam in Bulgaria are a precondition for attempting to formulate new questions and build various hypotheses reflecting the dynamic reality of the relations between religious communities.

The results of the analysis of European Values Study data (European 
Values Study -2008$)^{2}$ indicate significant differences between the respondents who have defined themselves as affiliated to Eastern Orthodox Christianity and to Islam. ${ }^{3}$ It is precisely through comparison that we distinctly see the difference between declared religious affiliation and a complete religious identity. Among Eastern Orthodox Christians, there is a considerably more significant internal differentiation in indicated opinions and assessments than among Muslims. Those who have defined themselves as Muslims display a higher level of personal integration as regards their value orientations than do Christians or people of other religious confessions.

Along with this, a comparison between different religious groups in the study clearly reveals that the profile of atheism has practically lost a great part of its value orientations. Outside the declared non-affiliation it involves with respect to a specific religion, atheism practically does not involve any specific value or social orientations of its own.

To this we should add the fact that this survey of values in Bulgaria is the first in which a comparatively lower share of respondents have clearly indicated affiliation to Eastern Orthodoxy (58,6 \%). The mechanical declaring of religious affiliation is gradually giving place to fuller, better integrated sets of values, and this trend seems more distinct among the Muslims. That is why the chosen research hypothesis can be confirmed and partially modified on the basis of the findings. Regardless of various differences internal to the Muslim group, the results show a higher degree of integration at the level of

\footnotetext{
2 The survey data are accessible at the Internet address of the Bulgarian Sociological Association: http://www.bsa-bg.org

3 The lack of space in this article for a precise distinction between the sub-groups of Sunni and Shiite Muslims has lead to generalizations that might, to a certain degree, obscure the essential distances between these two divisions in Islam.
}

values (Bosakov 2009). This gives us reason to continue our research in the direction of the basic elements of the hypothetical set of value orientations that corresponds to the Islamic religious identity in present-day Bulgarian society.

The data show that, among those who indicate religion, work and family as very important in their lives, there is a greater share of respondents self-defined as Muslims. At this stage of analysis we may say that it is around these three spheres that the most clearly discernable groups of value orientations are concentrated, those for which we may claim with a high degree of probability that they are the value orientations of Muslims in Bulgaria. While among all respondents, taken as a whole, religion is relatively less often defined as a leading value for the respondent, its importance for Muslims is predominant.

Among those who have indicated religion as very important for their lives, Muslims amount to $31,1 \%$, while the percentage of all respondents who have given this answer is $12.8 \%$. The proportion of Eastern Orthodox who have indicated this answer shows it to be a much rarer choice for them than for Muslims (54,0\% of all those who indicated this answer declared they were Eastern Orthodox, although the relative share of this religion among all respondents is much larger $58,6 \%)$. There is a similar distribution of answers to the questions regarding the importance of work; it is only with regard to the family that a clear similarity between representatives of the two religions is registered.

Among those who have indicated religion as very important in their lives, the share of Muslims is three times as high as that of all other surveyed persons. The results show that relatively young people (aged between 18 and 24) are those who have selected this answer more often. The answer was given more often by women 
than men, and by residents of villages and small towns three times more often than by those of larger settlements. The social profile of those for whom religion is very important or important in their lives can be related to the existing inequalities between centre and periphery in the context of the growing differences by income and education, and this profile usually corresponds to a traditional type of family. For the predominant share of these people, religion is a factor that structures their whole lifeworld, defines the distances to others and the general meaning of attitudes to the family and work.

The findings, compared with those of the previous EVS waves, provide grounds for formulating the hypothesis that in the last ten years the importance of religion has generally changed in Bulgarian society (Fotev 2000). But whereas the predominant secular values have expanded their influence among the group of Christians, among Muslims in Bulgaria there is a process of strengthening of Islam as a set of values and of consolidation of the community around Islamic values. Hence, the discussion below will be devoted to the influence of the religious value system on the attitude of Muslims towards modern values and social practices.

Apart from the topic of religion, work, and family, Muslims indicating the other three sets of values, leisure time, friends and acquaintances, and politics, as very important to them are a smaller percentage than the overall percentage of this religious group within the total population. The difference in percentages is greatest as concerns the importance of 'leisure time' (only 9,1\% of those who indicated this as very important for them were Muslims, whereas the share of Muslims in the total population is $12,8 \%$ ). Next in order of importance come 'friends and acquaintances', where $9,4 \%$ of those who indicated this answer were Muslims, and, slightly higher, 'politics', indicated as very important by $10,0 \%$ of Muslims.

Regardless of the distinct structuring of more important and less important value spheres in the lives of Muslims, in these six sets of values there are elements pertaining both to private and to public life. It is notable that the group of Muslims directs its attention in a greater degree to "inner" values, which regulate the intimate everyday lifeworld, such as 'religion' and 'family', while among their important values related predominantly to some sort of public interaction, 'work' is foremost.

The distribution of items defined as most important in the life of a person, and the exceptionally high share of Muslims who indicated religion as important compared with results for all other values, permits us to take the next step in this analysis and formulate one of its basic research theses: religion is not simply a value preferred and important for Muslim. All research findings give us reason to assert that, for the predominant share of the surveyed Muslims, religion represents an integral value scale upon which all other values are projected and acquire meaning. Religion as an integral value system is a structuring factor of the attitude to the other spheres of personal and public life. The religious ethics of Islam influences to a decisive degree the expressed attitude to the other values.

A comparison with the other religious communities, and especially with Eastern Orthodox Christians, does not show a similar process occurring there. The declared affiliation with Christianity, once placed in a different value context, begins to waver or takes on a different form. The results of this analysis give us reason to formulate the research hypothesis that there are significant changes taking place in religious consciousness in the past years, changes that have led to a relative decrease in the 
importance of religious morality among the largest group, that of Christians, and, on the contrary, to a consolidation of religious morality among Muslims. The testing of this hypothesis should be the object of an additional, full-scale analysis, but here we may claim that the religious dimension can be found in practically all issues related to everyday life, public interaction, and accepted values of the surveyed groups.

\section{REFERENCES}

Bosakov, V. 2006. Identity and Variety of Islam in Bulgaria. Sofia: Virtual Centre for Music, Culture, and Scientific Research (in Bulg.).

Bosakov, V. 2009. Value Orientations of Muslims in Bulgaria. In: Fotev, G. (ed.) 2009. European Values in Present-day Bulgarian Society. Sofia: University Publishers St. Kliment Ohridski. pp. 197-217 (in Bulg.).

Bosakov, V. 2010. The Integration of Muslims in Bulgaria. Sofia: Ivrai Pbls. (in Bulg.).
Bosakov, V. 2015. Islam and Mofernity. Mutual Challenges. Sofia: Ivrai Pbls. (in Bulg.).

Pamporov, A. 2009. Social Distances and Ethnic Stereotypes for Minorities in Bulgaria. Sofia: Open Society Institute (in Bulg.).

Fotev, G. (ed.) 2000. Neighbourhood of Religious Communities in Bulgaria. Sofia: Institute of Sociology. Bulgarian Academy of Sciences (in Bulg.).

Fotev, G. (ed.) 2009. European Values in Presentday Bulgarian Society. Sofia: University Publishers St. Kliment Ohridski (in Bulg.).

Galabov, A. 2007 Qualitative Dimensions of the Young People's World. In: R. Bachvarova, A. Galabov, M. Mirchev. A Diverse Generation. The Young People of Bulgaria at the Threshold of Europe. Sintesi. Milano: Bruno Mondadori. pp. 201-271.

Fotev, G. 2003. Civil Society against Balkanization. In: Dane, R. and David C. Durst (editors) Civil Society in Southeast Europe. Amsterdam-New York: VIBS. 